\title{
Don't Kiss My Bumper: Investigating Tailgating Driving Behaviour in Botswana
}

\author{
Kagiso N. Thabano, Monde Kote, Mpho M. Pheko, Nicole Monteiro, \\ Shyngle K. Balogun \\ Department of Psychology University of Botswana
}

\begin{abstract}
The current study investigated the prevalence of tailgating behaviour among drivers in Gaborone city, Botswana. The study further explored gender differences among drivers who tailgate. Data were collected at three sets of traffic lights situated in the north, west and east sides of Gaborone. At any given time data was collected by at least one team made up of four researchers over three days, and during rush and non-rush hours. A total of 722 vehicles were measured and recorded and the results revealed that tailgating, using a VW Polo length of three and a half meters is prevalent among drivers in Botswana. Furthermore, male drivers engaged in more tailgating behaviour than their female counterparts. Additionally, tailgating behaviour was more prevalent during peak hour compared to during non-peak hour period. Considering that in Botswana little if any research has been documented on risky driving behaviour in general and specifically on tailgating behaviour, findings of the current study will bring to the table a discussion on safe following distance and the risks thereof, and inspire research on risky driving behaviour. Additionally, the findings can be useful in relevant policies and in establishing effective tailgating treatment programmes.
\end{abstract}

Keywords: tailgating, gender, Gaborone, Botswana.

\section{Introduction}

Health related studies have shown particular interest in understanding risky behaviours. Notably, risky driving behaviours, which are chief amongst the causes of road traffic accidents (RTAs), account for $95 \%$ of all fatal crashes (Petridou \& Moustaki, 2000). Penden et al (2004), highlight that injuries resulting from RTAs are a major but neglected public health issue globally. Further, although people use many systems on a daily basis, road transport is the most complex and dangerous. Almost a decade ago, across the globe, it was estimated that approximately 1.2 million people were killed in RTAs yearly, with the number of injuries approximated at 50 million (Peden et al. 2004). The World Health Organisation (WHO)'s 2002 data ranked RTAs as the $11^{\text {th }}$ leading cause of death, accounting for 23 percent of all injury deaths across the globe (Penden et al., 2004). Moreover, according to the World Health Organisation's second global status report on road safety released in 2012 , injuries resulting from road traffic accidents take the lives of approximately 1.3 million people yearly, an increase from the earlier report. The report also highlights that should the current trends persist, road collisions are predicted to rise from their current position as ninth leading cause of death to become the fifth leading cause of death by 2030 (WHO, 2009). Given other statistics which suggests that, within a decade road collision moved from being the $11^{\text {th }}$ cause of death to become the $9^{\text {th }}$ cause, concerted efforts to ascertain effective and viable prevention is needed (Penden et al., 2004).

Of the total deaths resulting from RTAs, about $90 \%$ of them take place in low- and middle-income countries, and according to the WHO report, if action is delayed, the statistics of injuries and deaths related to road traffic is likely to keep on rising in most regions of the world as motorisation increases (WHO, 2009). According to LEDUC Media's World's Life Expectancy website RTAs are in the top 20 causes of deaths in Botswana. Specifically, road traffic accidents are ranked as number 9 in the leading causes of deaths in Botswana. Globally, Botswana is ranked $42^{\text {nd }}$ in RTAs, with an age adjusted death rate of $26.61 \%$ per 100,000 people (World's Life Expectancy, 2013). While mortality and injuries due to road traffic accidents is a huge problem in developing countries, research on the subject, RTAs and consequences thereof does not match the magnitude of the problem (Nantulya \& Reich, 2002). It is thus vital to carry out research in Botswana seeking to identify risky driving behaviours.

A range of human and environmental factors contribute to RTAs. Environmental factors include weather and climate, law enforcement practices, vehicles characteristics and road design and maintenance (WHO, 2004). Driver behaviours that play a role in RTAs or the severity of injuries following RTAs include failing to wear a seatbelt, driving while drowsy, speeding, alcohol and drug use and tailgating among others (Blows, Ameratunga, Ivers, Lo, \& Norton, 2005; Petridou \& Moustaki, 2000; WHO, 2004). Even so, the scope 
of the current study will be limited to driver behaviour even while not minimising the contribution of environmental factors to RTAs.

Many drivers opt to drive and conduct themselves in ways that heighten their risk of having an accident and this is evidenced by documented research on the relationship between: the number and severity of RTAs and speed (Christensen \& Amundsen, 2004); the relationship between seat-belt non-use and elevated risk of injury and death during an RTA (National Highway Traffic Safety Administration, 2005b); and the association between driver distraction and inattention and crashes (Treat et al. 1979; Hendricks, Fell \& Freedman, 1999). In fact, even as far back as 1979, Treat and colleagues' epidemiological study which investigated the frequency at which a variety of variables add (definite, probable or possible) to RTAs found that human error such as risky driving behaviour contributed to traffic crashes more than environmental and vehicle factors. Similar findings were noted in a more recent study employing a similar method (epidemiology), the human error factor was most frequently cited as contributing to crushes (Hendricks, Fell \& Freedman, 1999).

It has been noted that male drivers are involved in more TRAs than female drivers, and this can be expected considering that there are more males on the roads than females (Parker \& Stradling, n. d). Even so, not much is said on gender differences in tailgating behaviour specifically except in risky behaviour in general.

Some research (Ludwig \& Geller, 1997; 2000) suggests that individuals who engage in a potentially risky driving behaviour have a likelihood of engaging in several other such behaviours. In the latter study, a monograph which described more than 15 years of research on pizza delivery drivers, drivers who learned to engage in a specific safe driving behaviour were likely to engage in several other safe behaviours. Consequently, driving behaviours, whether risky or safe need not be considered in isolation. In an analysis of routinely reported rear end accidents in South Australia, data for 1998-2002 investigated by the Centre for Automotive Safety Research revealed that relative to other crashes, rear end crushes are more likely to take place near crossroads, during peak traffic times, in daylight, and on straight roads among others. Rear end crushes are less likely to happen at night, on weekends, and on undivided roads, highlighting traffic density (Baldlock, Long, Lindsay \& McLean, 2005). It has been documented that two major causes of rear-end accidents are tailgating and driver-inattention, the former being considered the major contributing cause and the most dangerous (Carter, May, Smith \& Faiclough, 1995; National Highway Traffic Safety Administration, 2005). The current paper will be limited to the former, tailgating.

Finding documented official statistics and/or peer reviewed articles on tailgating in Botswana was almost impossible, necessitating comparison with other established guidelines. The guidelines by the New Jersey Motor Vehicle Commission (n. d.) are that drivers should keep one car length for each 10 miles per hour of speed. Others have suggested that following another vehicle less than two seconds should be considered dangerous (Hutchinson, 2008). Some guidelines recommend that when stopped in traffic, the driver must maintain one to two car lengths following distance. This reduces the risk of being hit from behind and gives the driver the freedom to move within one meter in cases where other vehicles are stopped behind. It is also important to highlight that following distance increases with movement or speed among other conditions. (Transport Roads and Maritime Services, n.d) In the case of the current study, vehicles were measured when stopped, safe following distance was considered to be three and a half meters - as measured using the length of a VW Polo sedan, comparatively a very small car. Thus tailgating was considered to be any distance less than three and a half meters.

The Botswana government has tried a variety of measures to curb RTAs in the country. These preventative measures include: road safety education, speed traps, the use of booze buses and increasing public holiday days over the Independence, Christmas and New Year's holidays. Furthermore, public servants are allowed half day to enable them to travel early for long weekends. Even so, according to the statistics for 2001 - 2011 provided by the Traffic Headquarters office, road accidents continue to claim the lives of many and to leave many people injured (Traffic Headquarters, 2012). This suggests that to some degree drivers possibly engage in risky driving behaviours. Better documented is the contribution of drunken driving to TRAs in Botswana as evidenced in policy measures (i.e., raising the alcohol levy and stationing booze buses along the highway during public holidays to discouraging drinking and driving behaviours).

To get insight on tailgating and possibly inform policy geared towards curbing RTAs it is necessary to have documented research on tailgating behaviour. Such research will answer the questions of: what percentage of Batswana tailgate, who is more likely to tailgate, and whether tailgating prevalence differs according to time of day [rush hour versus non-rush hour]. In that light, the current study investigated tailgating behaviours of drivers in Gaborone, Botswana's capital city during peak and non-peak driving hours. The study was guided by the following research questions:

1. What percentage of drivers tailgate?

2. Are there gender differences in the observed tailgating behaviour among drivers?

3. Does tailgating behaviour differ for peak driving hours and non-peak driving hours? 
The purpose of the current study is thus to highlight tailgating behaviour in Gaborone, establish the prevalence of tailgating behaviour in Gaborone, and to examine gender, and time of day differences in tailgating behaviour of drivers. In that light, it was hypothesised that:

1. Men will tailgate more than women regardless of time of day.

2. Tailgating will be more prevalent during peak driving hours than during non-peak driving hours?

\section{Participants}

\section{Methodology}

The distance maintained by the vehicle behind was measured in 722 vehicles across Gaborone city; 238 vehicles at Airport Junction - Phakalane, 250 vehicles at Molapo Crossing, and 234 vehicles at Faculty of Engineering Technology (FET)-Boitekanelo College Traffic lights. The observed drivers included 541 males and 181 females. These statistics are shown in table 1 below.

Table 1. Participants

\begin{tabular}{|l|l|l|}
\hline & Frequency & Percent \\
\hline Male & 541 & 74.9 \\
Female & 181 & 25.1 \\
& 722 & 100.0 \\
\hline Airport Junction & 238 & 33.0 \\
Molapo Crossing & 250 & 34.6 \\
FET & 234 & 32.4 \\
Total & 722 & 100.0 \\
\hline
\end{tabular}

\section{Rationale for Site Selection}

The Airport Junction-Phakalane set of lights are situated in the north of Gaborone and therefore are the main entry for populations who commute from at least five villages in Gaborone's north, besides northern suburbs. The Molapo Crossing set of lights on the other hand are the main entry for populations who commute from at least three villages in Gaborone's west, besides western suburbs. The FET - Boitekanelo College set of lights are one of the gateways into the city from the eastern suburbs. In that light, it can be expected that these areas will have traffic congestion and that the traffic congestion in these areas will differ for peak and non-peak driving hours. This will thus enable observation of tailgating behaviour for peak and non-peak driving hours.

\section{Materials}

Two professional tape measures and ready-made record sheets were utilised.

\section{Procedure}

Data was collected at three different sets of traffic lights in Gaborone over four days; Airport JunctionPhakalane on Monday, Molapo Crossing on Tuesday/Thursday, and FET-Boitekanelo College on Wednesday. These three sites were chosen considering that they are among the set of lights that are a gateway into the city from surrounding villages. As such, they were considered strategic for traffic flow purposes.

At each site data was collected on two different times of the day, rush hour ( $7 \mathrm{am}-8 \mathrm{am})$ and non-rush hour $(2.30 \mathrm{pm}-3.30 \mathrm{pm})$. Consequently, data was collected at each site for a total of two hours. Data was collected for two hours to observe enough motorists for reliable data collection, and at different times to allow for possible rush hour and non-rush hour effects. Although data was to be collected on Monday through to Wednesday only, due to power cuts affecting the Molapo Crossing traffic lights on Tuesday afternoon, the researchers re-scheduled to collect data at this site on Thursday afternoon instead.

Data was collected by a team of four researchers at a time; the recorder, the watchman and two measurement takers. The two measurement takers used a measurement tape to record the distance between the rear of the front car and the front of the rear car. The measurement takers then had to state the measurement, type of car, and the sex of the driver loud enough for the recorder to hear amidst the traffic. The recorder, who kept a close distance to the measurement takers, wrote the indicated information in a ready-made record sheet. The recorder also had to record whether there was a traffic officer on site, the gender thereof, and the location of 
the traffic light, being Airport Junction-Phakalane, Molapo Crossing or Faculty of Engineering Technology (FET)-Boitekanelo College lights. At all times there were at least four researchers (1 team) on site collecting data. Data was collected when cars had stopped, and not when they were in motion.

\section{Results}

Frequency table (table 2) and bar chart (figure 1) are shown for vehicle following distance measured. Of the observed cars, 472 drivers (65.3\%) kept a following distance below three meters, 149 drivers $(20.6 \%)$ kept a following distance between three and four meters, and 101 drivers (14\%) kept a following distance between five and six meters.

Table 2. Frequency - Vehicle Following Distance

\begin{tabular}{|c|r|r|}
\hline Distance Measured & Frequency & Percent \\
\hline 0-2 meters & 193 & 26.7 \\
$2-3$ meters & 279 & 38.6 \\
$4-5$ meters & 149 & 20.6 \\
5-6 meters & 101 & 14.0 \\
Total & 722 & 100.0 \\
\hline
\end{tabular}

Figure 1. Frequency - Vehicle Following Distance

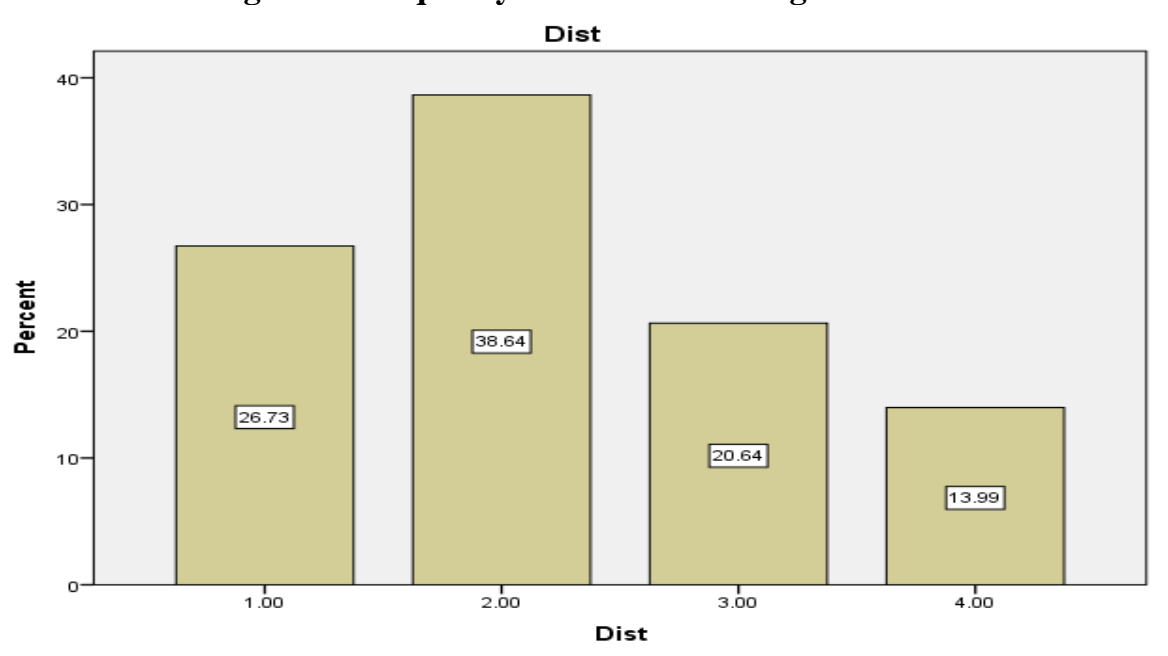

Analysis utilising crosstabs and chi-square (Table 3) shows that in following distance measured there was a significant difference in whether the driver was male or female. Male drivers were more likely than female drivers to drive at a following distance below two meters, $X^{2}=8.529(P=.04)$. Also, drivers' following distance differed significantly between peak and non-peak hour periods, $\mathrm{X}^{2}=30.785(\mathrm{P}=.00)$ as shown in Table 4.

Table 3. Crosstabs - Distance and Gender

\begin{tabular}{|c|c|c|c|c|c|}
\hline & & \multicolumn{2}{|c|}{ Driver Gender } & \multirow[t]{2}{*}{ Total } & \multirow{2}{*}{$\begin{array}{c}\text { Pearson Chi- } \\
\text { Square }\end{array}$} \\
\hline & & male & female & & \\
\hline \multirow{4}{*}{ Dist } & $0-2$ meters & 159 & 34 & 193 & $\begin{array}{l}8.529 * \\
\mathrm{P}=.04\end{array}$ \\
\hline & 2-3 meters & 201 & 78 & 279 & \\
\hline & 4-5 meters & 105 & 44 & 149 & \\
\hline & 5-6 meters & 76 & 25 & 101 & \\
\hline Total & & 541 & 181 & 722 & \\
\hline
\end{tabular}


Table 4. Crosstabs - Distance and Observation Time

\begin{tabular}{|c|c|c|c|c|c|}
\hline & \multicolumn{2}{|c|}{ Time of Observation } & \multirow[t]{2}{*}{ Total } & \multirow{2}{*}{$\begin{array}{c}\text { Person } \\
\text { Chi- } \\
\text { Square }\end{array}$} \\
\hline & & $\begin{array}{c}\text { Morning Rush } \\
\text { Hour }\end{array}$ & \begin{tabular}{|c|} 
Afternoon Non- \\
Rush Hour
\end{tabular} & & \\
\hline $\begin{array}{l}\text { Dist } \\
\text { Total }\end{array}$ & $\begin{array}{l}\text { 0-2 meters } \\
\text { 2-3 meters } \\
\text { 3-4 meters } \\
\text { 4-5 meters }\end{array}$ & $\begin{array}{r}131 \\
164 \\
65 \\
41 \\
401\end{array}$ & $\begin{array}{r}62 \\
115 \\
84 \\
60 \\
321\end{array}$ & $\begin{array}{l}193 \\
\\
279 \\
149 \\
101 \\
722\end{array}$ & $\begin{array}{l}30.785 \\
\mathrm{P}=.00\end{array}$ \\
\hline
\end{tabular}

\section{Discussion}

Findings of the current study answer the research questions and support both hypotheses 1 and 2 . Tailgating behaviour is prevalent among drivers in Gaborone and there are gender differences in tailgating. Furthermore, tailgating behaviour does differs significantly between peak and non-peak hour periods.

The findings highlight that as observed elsewhere (Minnesota DOT, 2006) tailgating is prevalent among drivers and potentially a factor in many rear-ends crushes. In the current study, tailgating behaviour was very high even without looking at drivers who followed at a distance between three meters and three and a half meters. This suggests that drivers tailgate by large margins. In other words, drivers tailgate period. The findings go further to indicate that the prevalence of tailgating behaviour can be observed more among male drivers. This suggests that male drivers are more risky in following distance while female drivers appear to be more careful of the following distance. This potentially speaks of high documented numbers of males involved in RTAs (Botswana Traffic Headquarters, 2012; Parker \& Stradling, n. d), rear-end crashes possibly included and it has been noted that rear-end crashes result mostly from tailgating besides distracted driving.

Also, as expected, tailgating behaviour was more prevalent during peak hour compared to during nonpeak hour period. Considering that tailgating is among chief causes of rear-end crashes (Carter, May, Smith \& Faiclough, 1995; National Highway Traffic Safety Administration, 2005), and that such crashes are more likely to happen during peak traffic times (Baldlock, Long, Lindsay \& McLean, 2005), it is not surprising that tailgating was found to be more prevalent during peak hour period compared to non-peak hour period.

A possible explanation of tailgating prevalence could be that drivers in general do not consider vehicle following distance to be an important road safety measure particularly that across the country no sign or bill board cautions drivers on following distance. Even while the absence of road signs or bill boards cautioning drivers of risky following distance may seem to suggest that law enforcement is silent on tailgating behaviour, worth noting is the fact that in cases of rear-end crashes, the rear vehicle is found to be at fault on the basis that it was likely following at an unsafe distance. In case drivers are cautious of the risks of following another vehicle too close, it is possible that drivers cannot accurately determine a safe following distance. It is worth noting that during the study some drivers were observed to follow at less than 100 centimetres, suggesting the possibility that if this had been a large study spanning beyond three days more such risky following distance could be noted more.

\section{Counclusion}

Tailgating behaviour is prevalent in Gaborone, Botswana. A majority of drivers followed other vehicles way below the three and a half meter mark used by the researchers. Furthermore, tailgating behaviour is more prevalent among males compared to their female counterparts. In general, it is possible that drivers are not aware of and/or cannot accurately determine safe following distance, especially since road signs and bill boards are silent on safe following distance. Research though, has highlighted the significance of establishing effective means to help drivers keep safe following distance (Wang \& Song, 2009; Rama \& Kulmala, 2000).

\section{Limitations}

The current study was more of a pilot study meant to highlight tailgating prevalence. The study did not measure following distance while vehicles were in motion, a standard commonly used across the globe; as such it is possible that tailgating prevalence is under-reported in that observing vehicles in motion could have revealed an even higher prevalence rate in tailgating behaviour. 


\section{Recommdneations}

Follow up research is needed using tailgating standards that are usually followed internationally (i.e. the 3 second rule) to get a more accurate picture of tailgating prevalence in Botswana. Even before then, on the basis of the current findings, tailgating treatment means are needed. Establishing effective ways to help drivers keep proper vehicle headways and to caution and discourage tailgating behaviour is important (Wang \& Song, 2009) and tailgating treatments such as warning signs have been found to reduce the speed and increase following distance (Rama \& Kulmala, 2000). Several States in The United States have effectively implemented tailgating treatment projects which significantly reduced tailgating. Such treatments included reflective dots on the roadway, pavement markings and signs that help drivers gauge their following distance, information signs and strong public campaigns (Minnesota DOT, 2006). Traffic authorities in Botswana could emulate the above and implement tailgating treatments such as reflective dots on the roadway, pavement marking, information signs and public campaigns among others. Even more, bumper stickers cautioning drivers about tailgating can be effective.

\section{Impact On Industry}

In Botswana little if any research has been documented on risky driving behaviour in general and specifically on tailgating behaviour. Findings of the current study will thus bring to the table a discussion on safe following distance and the risks thereof, and inspire research on risky driving behaviour in general. Additionally, the findings can be useful in relevant policies and in motivating the establishment of effective tailgating treatment programmes.

\section{Ackowledgements}

The authors would like to thank other Traffic Psychology and Accident Prevention Research Team who helped in data collection for the current study: Dr Seipone Mphele, Mosebetsi M. Selemogwe and Rapelang Chilisa. Preliminary results of this research will also be presented at the Symposium on Traffic Psychology and Accident Prevention at the University of Botswana.

\section{References}

[1]. Baldock, M. R. J., Long, A. D., Lindsay, V. L., \& McLean, A. J. (2005). Rear end crashes. Report CASR 018, Centre for Automotive Safety Research, University of Adelaide.

[2]. Blows, S., Ameratunga, S., Ivers, R. Q., Lo, S. K., \& Norton, R. (2005). Risky driving habits and motor vehicle driver injury. Accid Anal Prev, (4), $619-624$.

[3]. Botswana Traffic Headquarters. (2012). Accident, Fatality and Injury statistics for $2001-2011$.

[4]. Carter, C., May, A. J., Smith, F. J., \& Fairclough, S. H. (1995). An evaluation of in-vehicle headway feedback system. In S. A. Robertson (Ed.), Contemporary Ergonomics, 287-292. London: Taylor and Francis.

[5]. Hendricks, D. L., Fell, J. C., \& M. Freedman. (1999). The relative frequency of unsafe driving acts in serious traffic crashes. DTNH22-94-C-05020. Washington, DC: National Highway Traffic Safety Administration.

[6]. Hutchinson, P. T. (2008). Tailgating. Safety Centre for Automotive Safety Research, University of Adelaide, Australia, Research Report \# CASR046.

[7]. Klauer, S. G., Sudweeks, J., Hickman, J. S., \& Neale, V. L. (2006). How risky is it? An assessment of the relative risk of engaging in potentially unsafe driving behaviors.

[8]. Ludwig T. D., \& Geller E. S. (2000). Intervening to improve the safety of delivery drivers: A systematic behavioral approach. Journal of Organizational Behavior Management, 19((4)):1-124.

[9]. Ludwig T.D., \& Geller E.S (1997). Assigned versus participative goal setting and response generalization: Managing injury control among professional pizza deliverers. Journal of Applied Psychology, 82((2)):253-261.

[10]. Minnesota DOT. (2006). Minnesota Tailgating Pilot Project, Report and Summary. http://www.dot.state.mn.us/trafficeng/tailgating/index.html. Accessed on 20 February 2013.

[11]. Nantulya, V. M., \& Reich, M. R. (2002). The neglected epidemic: Road traffic injuries in developing countries. Br. Med. J., 324, $1139-1141$.

[12]. NHTSA (2005). Analysis of speeding related fatala motor vehicle traffic crashes. U.S. Department of Transportation, National Highway Traffic Safety Administration; DOT HS 809 839. Accessed on 13 February 2013.

[13]. NHTSA (2005b). Motor Vehicle Traffic Crash Fatalities and Injuries. 2004 Projections. DOT HS 809862 Washington, DC: National Highway Traffic Safety Administration. www-nrd.nhtsa.dot.gov/pdf/nrd-30/NCSA/PPT/2004EARelease.pdf. Accessed on 13 February 2013.

[14]. Parker, D., \& Stradling, S. (n.d.) Driving Behavior Research Group Department for Transport - Influencing Driver Attitudes and Behavior (No. 17). http://www.parliament.wa.gov.au/intranet/libpages.nsf/WebFiles/ITS++ road+article+Parker/\$FILE/road+article+Parker.pdf. Accessed on 20 February 2013.

[15]. $\quad$ Penden, M., Scurfield, R., Sleet. D., Mohan. D., Hyder, A. A., Jarawan. E., \& Mathers, C. (2004). World Report on Road Traffic Injury Prevention. World Health Organisation, Geneva.

[16]. Petridou, E., \& Moustaki, M. Human factors in the causation of road traffic crashes. European Journal of Epidemiology 2000; 16 (9), $819-826$

[17]. Rama, P., \& Kulmala, R. (2000). Effects of variable message signs for slippery road conditions on driving speed and headways. Transportation Research F, 3 (2), 85 - 94.

[18]. Roadway Safety Foundation (2001). Saving lives: RFS recognizes nine outstanding highway safety projects. Road Safety Reporter.

[19]. Transport Roads and Maritime Services, (n.d). A guide to the driving test. New South Wales Governement. Australia. http://www.rta.nsw.gov.au/licensing/downloads/guide_driving_test.pdf. Accessed 19 February 2013. 
[20]. Treat, J.R., Tumbas, N. S., McDonald, S .T., Shinar, D., Hume, R. D., Mayer, R. E., Stansifer, R. L., \& Catellan, N. J. (1979). TriLevel Study of the Causes of Traffic Accidents: Final Report Volume I: Causal Factor Tabulations and Assessments, Institute for Research in Public Safety, Indiana University, DOT Publication No. DOT HS-805 085.

[21]. WHO (2004). World Health Statistics.http://apps.who.int/iris/bitstream/10665/44844/1/9789241564441_eng.pdf. Accessed on 2 March 2013.

[22]. Who (2009). Global Status Report on Road Safety. http://whqlibdoc.who.int/publications/2009/9789241563840 eng.pdf. Accessed on 2 March 2013.

[23]. World health rankings (2013). Health Profile Botswana. http//www.worldlifeexpectancy.com/Botswana-road-traffic-accidents. Accessed on 2 March 2013. 